\title{
DEVELOPMENT AND VALIDATION OF METHODS FOR QUANTITATIVE DETERMINATION OF SODIUM HYALURONATE IN THE COMPOSITION OF COMBINED DENTAL GEL
}

\author{
Dmytro Orlenko \\ Department of Industrial Pharmacy and Economics ${ }^{1}$ \\ Volodymyr Yakovenko \\ Department of Industrial Pharmacy and Economics ${ }^{1}$ \\ Vyacheslav Plastun \\ Department of Pharmaceutical Development \\ LLC "Experimental Plant DNCLZ" \\ 8 Vorobyova str., Kharkiv, Ukraine, 61057 \\ Liliia Vyshnevska \\ Drug technology Department ${ }^{1}$ \\ ${ }^{1}$ National University of Pharmacy \\ 53 Pushkinska str., Kharkiv, Ukraine, 61002
}

\begin{abstract}
According to the EP monograph "Sodium hyaluronate" for identification they use the infrared transmission spectrum of the substance, quantification is carried out by spectrophotometry.

The aim of the work was to develop a method for quantitative determination of hyaluronic acid in the gel in the presence of other substances and its validation.

Materials and Methods. The object of the study were samples of combined dental gel of the following composition: metronidazole benzoate $16 \mathrm{mg} / \mathrm{g}$, miramistin $5 \mathrm{mg} / \mathrm{g}$, sodium hyaluronate $2 \mathrm{mg} / \mathrm{g}$. Identification and quantification of sodium hyaluronate was performed by liquid chromatography ( $\mathrm{SPhU}, 2.2 .29,2.2 .46)$. The test solution and the reference solution were chromatographed, obtaining the number of parallel chromatograms not less than when checking the suitability of the chromatographic system. Chromatography is performed on a liquid chromatograph with a diode-matrix detector under the following conditions: chromatographic column PL-aquagel-OH, Agilent size $300 \times 7.5 \mathrm{~mm}$, with a particle size of sorbent $8 \mu \mathrm{m}$; mobile phase A: $0.1 \mathrm{M}$ sodium sulfate solution; mobile phase B: acetonitrile for chromatography P; detection at a wavelength of $210 \mathrm{~nm}$.

Results. The retention time of sodium hyaluronate on the chromatogram of the test sample of the gel coincides with the peak and the retention time on the chromatogram of the comparison solution of the standard sample of the substance. The suitability of the chromatographic system for 3 parallel determinations was checked: the relative standard deviation (RSD) is equal to 0.25 , the number of theoretical plates is 980 , the symmetry coefficient is 1.293 . The validation characteristics of the developed methodology meet the established eligibility criteria. The spectral purity coefficients (Fp) of the sodium hyaluronate peak on the chromatograms of the model solution are $\mathrm{Fp} 1=997.665$ and $\mathrm{Fp} 2=997,802$. The method is linear in the range of sodium concentration of hyaluronate $80-120 \%$, the calculated linear dependence of the reduced area of the chromatographic peak on the reduced concentration of sodium hyaluronate is $|\mathrm{a}|=1.9490 \leq \Delta \mathrm{a}=2.56$. The confidence interval of the unit value for the sample of relations is found/entered $\Delta \mathrm{z}=1.08$, which corresponds to the condition $\Delta \mathrm{z} \leq 1.6 \%$. The value of the systematic error is equal to $\delta=0.12$, which satisfies the condition $\delta \leq 0.51 \%$.

Conclusions. The method of quantitative determination of sodium hyaluronate by the method of high-performance liquid chromatography has been developed and investigated. The method allows the identification and quantification of sodium hyaluronate in the composition of the dental gel, in the presence of metronidazole benzoate and miramistin. Validation of the methodology was performed and the main validation characteristics were determined. In terms of specificity, linearity, correctness, convergence of the method meets the eligibility criteria established by the SPhU.
\end{abstract}

Keywords: hyaluronic acid, high performance liquid chromatography, quantitative determination, validation of methods, dental gel. 


\section{Introduction}

Hyaluronic acid (HA) is a key element in the soft tissues of the periodontium and periodontal ligament, as well as in hard tissue such as alveolar bone, and performs many structural and physiological functions in these tissues [1].

Today HA is widely used in many branches of medicine with interesting potential applications in dentistry for the treatment of acute and chronic inflammatory disease. Data obtained from the present review of 20 clinical studies demonstrate that, due to its positive action on tissue repair and wound healing, topical administration of HA could play a role not only in postoperative dental surgery, but also in the treatment of patients affected by gingivitis and periodontitis, with a significant improvement in their quality of life $[2,3]$.

Hyaluronic acid is used as a single drug in the form of solutions, gels, injectable solutions, or in combination with antibacterial, antiseptic active pharmaceutical ingredients, vitamins, etc. [4-7].

The object of our research is a combined dental gel that contains hyaluronic acid and two active substances with antibacterial action: metronidazole and miramistin. Hyaluronic acid is a natural unsulfated glycosaminoglycan with a high molecular weight of 4000-20000000 [1]. Identification of hyaluronic acid as an active pharmaceutical ingredient (API) is carried out by various physicochemical methods. The simplest method is infrared spectroscopy using Fourier transform, also using high-resolution nuclear magnetic resonance spectroscopy [8]. The acidic properties of hyaluronate allow to obtain solutions in water of salts with alkali metals. Hyaluronic acid is an anionic linear polysaccharide with different molecular weight, which depends on the method of its production. The absence of isomerism, which is characteristic of most glucosaminoglycans, ensures the chemical identity of the obtained hyaluronates [9].

According to the monograph of the European Pharmacopoeia "Sodium hyaluronate", the infrared transmission spectrum of the substance is used for identification, which should be identical to the spectrum of the standard sample. Quantitative determination is performed by spectrophotometry using carbazole reagent, measuring the optical density at a wavelength of $530 \mathrm{~nm}[10,11]$. In addition to sodium hyaluronate, the developed gel contains metronidazole benzoate and miramistin. Our studies have shown that the method of absorption spectrophotometry does not allow a reliable quantitative assessment of the content of hyaluronic acid in the presence of other components of the drug, in particular metronidazole benzoate [12]. High-performance liquid chromatography (HPLC) is used to quantify hyaluronic acid or its decomposition products. This method allows the determination of hyaluronic acid in both biological fluids and in the composition of combined drugs. The HPLC method is characterized by high specificity and allows to level obstacles from excipients $[13,14]$.

The aim of the work was to develop an analytical method for the quantitative determination of hyaluronic acid in the gel in the presence of other substances and its validation.

\section{Materials and methods}

The object of the study were samples of combined dental gel of the following composition: metronidazole benzoate $16 \mathrm{mg} / \mathrm{g}$, miramistin $5 \mathrm{mg} / \mathrm{g}$, sodium hyaluronate $2 \mathrm{mg} / \mathrm{g}$. Hyaluronic acid in the form of sodium hyaluronate manufactured by Shiseido Co., LtD, Japan was used to make the gel.

The tests are performed by liquid chromatography (SPhU, 2.2.29, 2.2.46) [15].

Test solution. Place about $1000.0 \mathrm{mg}$ (exact amount) of the gel in a $25.0 \mathrm{ml}$ volumetric flask, make up to volume with the mobile phase, close tightly with a lid and shake vigorously to dissolve the gel. The solution is transferred to a centrifuge tube and centrifuged for $15 \mathrm{~min}$ at $10,000 \mathrm{rpm}$. The supernatant is filtered through a membrane fluoroplastic filter with a pore size of $0.45 \mu \mathrm{m}$, discarding the first $0.5 \mathrm{ml}$ of filtrate.

Comparison solution. About $40.0 \mathrm{mg}$ (exact amount) of sodium hyaluronate (PRS SPhU), pre-dried over phosphorus (v) oxide $\mathrm{P}$ in a vacuum oven (residual pressure $0.67 \mathrm{kPa}$ ) at a temperature of $60{ }^{\circ} \mathrm{C}$ for 5 hours, is placed in a volumetric flask with a capacity of $100.0 \mathrm{ml}$, add $60 \mathrm{ml}$ of water $\mathrm{P}$, maintain in an ultrasonic bath until the sample is dissolved, bring the volume of the solution with the same solvent to the mark and mix. 
Place $10.0 \mathrm{ml}$ of the resulting solution in a $50.0 \mathrm{ml}$ volumetric flask, make up to volume with the mobile phase and mix.

Chromatograph the reference solution to get from 2 to 4 chromatograms. For the areas of the sodium hyaluronate peak from the obtained chromatograms of the comparison solution, the relative standard deviation (RSD) is calculated. Obtaining parallel chromatograms $\left(\mathrm{n}_{0}\right)$ is stopped when the requirements set by $\mathrm{SPhU}$ to the $\mathrm{RSD}(\mathrm{SPhU}, 2.2 .46)$ are reached.

Chromatograph the test solution and the reference solution, obtaining the number of parallel chromatograms (n) not less than when checking the suitability of the chromatographic system $\left(\mathrm{n}_{0}\right)$.

Chromatography is performed on a liquid chromatograph with a diode-matrix detector under the following conditions:

- chromatographic column PL-aquagel-OH, Agilent size $300 \mathrm{~mm} \times 7.5 \mathrm{~mm}$, with a particle size of sorbent $8 \mu \mathrm{m}$, or similar, for which the requirements of the test "Checking the suitability of the chromatographic system" are met;

- mobile phase A: 0.1 M sodium sulfate solution;

- mobile phase B: acetonitrile for chromatography P;

- detection by wavelength: $210 \mathrm{~nm}$;

- mobile flow rate $-1.0 \mathrm{ml} / \mathrm{min}$;

- injection volume - $50 \mu \mathrm{l}$;

- column thermostat temperature $-40{ }^{\circ} \mathrm{C}$.

Chromatography is performed according to the gradient program shown in Table $\mathbf{1}$.

Table 1

Characteristics of the gradient program for chromatography

\begin{tabular}{cccc}
\hline Time (min) & Mobile phase A $(\mathbf{\%}, \mathbf{v} / \mathbf{v})$ & Mobile phase B $(\mathbf{\%}, \mathbf{v} / \mathbf{v})$ & Notes \\
\hline $0-2$ & 100 & 0 & Isocratic mode \\
$2-3$ & $100 \rightarrow 90$ & $0 \rightarrow 10$ & Linear gradient \\
$3-30$ & 90 & 10 & Isocratic mode \\
$30-31$ & $90 \rightarrow 100$ & $10 \rightarrow 0$ & Linear gradient \\
$31-40$ & 100 & 0 & Isocratic mode
\end{tabular}

The content of sodium hyaluronate $\left(\mathrm{X}_{1}\right)$ in $1 \mathrm{~g}$ of the drug, in milligrams, is calculated by the formula:

$$
X_{1}=\frac{S_{i} \times m_{0} \times 10 \times P \times 25 \times 1000}{S_{0} \times 100 \times 50 \times 100 \times m_{i}}=\frac{S_{i} \times m_{0} \times P}{S_{0} \times m_{i} \times 2},
$$

where $S_{i}$ - the average value of the peak areas of sodium hyaluronate, calculated from the chromatograms of the test solution; $S_{0}$ - the average value of the peak areas of sodium hyaluronate, calculated from the chromatograms of the comparison solution; $m_{0}$ - weight of a sample of a standard sample of sodium hyaluronate, in milligrams; $m_{i}$ - weight of the drug sample, in milligrams; $P$ - the content of the basic substance in the standard sample of sodium hyaluronate in terms of dry matter, as a percentage.

The content of sodium hyaluronate in $1 \mathrm{~g}$ of the drug should be from $1.90 \mathrm{mg}$ to $2.1 \mathrm{mg}$ at the time of release and during storage.

\section{Results}

The chromatograms of the test solution and the standard sample of sodium hyaluronate solution are shown in Fig. 1, 2. 


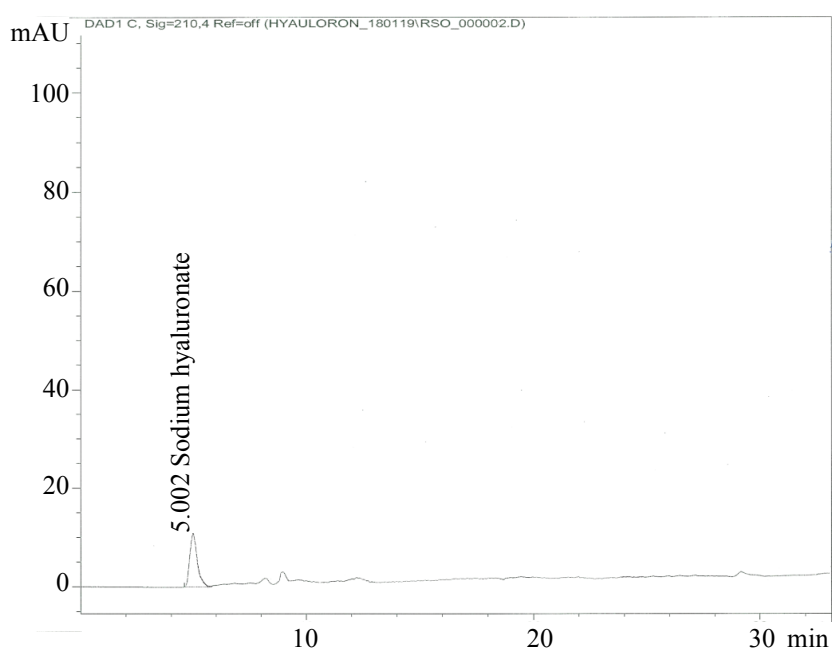

Fig. 1. Chromatogram of a standard sample solution of sodium hyaluronate.

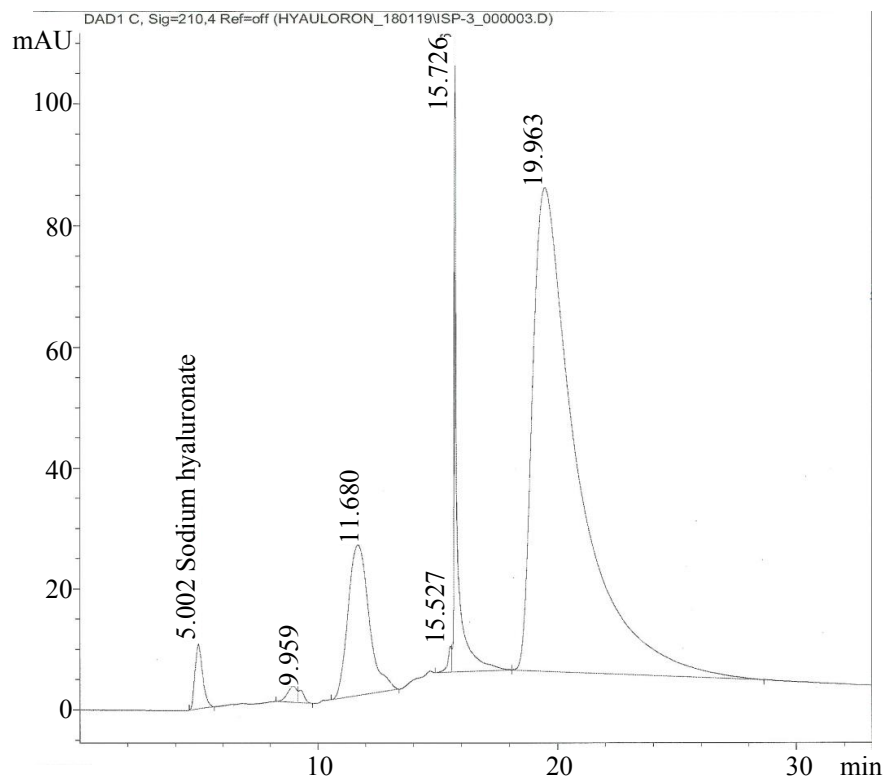

Fig. 2. Chromatogram of test gel solution for identification and quantification of sodium hyaluronate

Relative standard deviation (RSD) is calculated for the areas of sodium hyaluronate peak. Also evaluate the efficiency of the chromatographic column at the peak of sodium hyaluronate and the symmetry coefficient of sodium hyaluronate. criteria:

Checking the suitability of the chromatographic system has the following eligibility

- the relative standard deviation (RSD) of the areas of the sodium hyaluronate peaks obtained from the chromatograms of the reference solution must meet the requirements of $\mathrm{SPhU}$, 2.2.46 according to the number of parallel injections (Table 2);

- the number of theoretical plates calculated from the chromatograms of the comparison solution at the peak of sodium hyaluronate must be at least 500;

- the symmetry coefficient of the peak of sodium hyaluronate calculated from the chromatograms of the reference solution should not exceed 2.5;

The results are shown in Table 3, confirm that the requirements for the suitability of the chromatographic system are met for the minimum number of parallel injections. 
Table 2

Eligibility criteria for relative standard deviation

\begin{tabular}{ccccccc}
\hline & \multicolumn{5}{c}{ Number of parallel injections } \\
\cline { 2 - 6 } Indicator & $\mathbf{2}$ & $\mathbf{3}$ & $\mathbf{4}$ & $\mathbf{5}$ & $\mathbf{6}$ \\
\hline RSD, \% & $\leq 0.25$ & $\leq 0.67$ & $\leq 0.96$ & $\leq 1.19$ & $\leq 1.38$
\end{tabular}

Table 3

The results of checking the suitability of the chromatographic system

\begin{tabular}{|c|c|c|c|c|c|c|c|}
\hline \multirow{2}{*}{$\mathbf{n}_{\mathrm{i}}$} & \multirow{2}{*}{ Peak area $\left(S_{i}\right)$} & \multicolumn{2}{|c|}{ RSD, \% } & \multicolumn{2}{|c|}{$\begin{array}{c}\text { Column efficiency, number of } \\
\text { theoretical plates }\end{array}$} & \multicolumn{2}{|c|}{ Symmetry coefficient } \\
\hline & & Calculated & Requirements & Calculated & Requirements & Calculated & Requirements \\
\hline 1 & 244.85 & - & - & 985 & \multirow[b]{4}{*}{$\geq 500$} & 1.280 & \multirow{6}{*}{$\leq 2.5$} \\
\hline 2 & 245.327 & 0.14 & $\leq 0.25$ & 973 & & 1.277 & \\
\hline 3 & 244.127 & 0.25 & $\leq 0.67$ & 980 & & 1.293 & \\
\hline 4 & - & - & $\leq 0.96$ & - & & - & \\
\hline 5 & - & - & $\leq 1.19$ & - & & - & \\
\hline 6 & - & - & $\leq 1.38$ & - & & - & \\
\hline
\end{tabular}

The study of validation characteristics of the method of quantitative determination of sodium hyaluronate concerned the following characteristics:

- control of specificity of a technique;

- control of linearity of a technique;

- control of the correctness of the methodology;

- control of convergence of methods.

Criteria of acceptability at control of specificity of a technique:

- on the chromatograms of the placebo solution there should be no peaks with retention time in the ranges for sodium hyaluronate;

- the coefficient of spectral purity of the peak of sodium hyaluronate must be at least 995 $\left(F_{p} \geq 995.0\right)$.

The chromatograms of the reference solution and the chromatograms of the placebo solution are compared. The chromatogram of the reference solution for the sodium hyaluronate peak determines the retention times $\left(t_{R i}\right)$, the width of the peaks $\left(w_{i}\right)$ and the ranges $\left(t_{R i} \pm w_{i}\right)$. The research results are shown in Table 4.

Table 4

The results of studying the specificity of the method of quantitative determination

\begin{tabular}{|c|c|c|c|c|}
\hline & Chromatograms & & 1 & 2 \\
\hline \multirow{5}{*}{$\begin{array}{l}\text { Peak of sodium } \\
\text { hyaluronate }\end{array}$} & & $t_{R i}$ & 5.004 & 4,969 \\
\hline & Comparison solution & $\mathrm{w}_{\mathrm{i}}$ & 1.133 & 1,141 \\
\hline & & $\mathrm{t}_{\mathrm{Ri}} \pm \mathrm{w}_{\mathrm{i}}$ & $3.871-6.137$ & $3.828-6.110$ \\
\hline & & \multicolumn{2}{|c|}{ Combined range $t_{R i} \pm w_{i}$} & $3.828-6.137$ \\
\hline & Placebo solution & $\begin{array}{c}\text { The presence of placebo } \\
\text { peaks with a retention } \\
\text { time in the combined } \\
\text { range } t_{R i} \pm w_{i}\end{array}$ & absent & absent \\
\hline
\end{tabular}


The spectral purity (Fp) coefficients of the sodium hyaluronate peak calculated by the software complex of the rare chromatograph on the chromatograms of the model solution are $\mathrm{Fp} 1=997.665$ and $\mathrm{Fp} 2=997.802$. The obtained values meet the acceptability criterion $\mathrm{Fp} \geq 995.0$.

The specificity of the method of quantitative determination of sodium hyaluronate is confirmed by the fact that the chromatograms of placebo solution there are no peaks with a retention time in the range $t R i \pm w i$ for the analyte, therefore, placebo components do not affect the results obtained by the study method. The coefficients of the spectral purity of the analyte peak meet the criterion of acceptability and the studied technique has sufficient specificity.

Criteria of acceptability of control of linearity of a technique:

For the linear dependence of the given area of the chromatographic peak on the given concentration of the analyte content:

- the free member of the linear dependence must not exceed its confidence interval: $|\mathrm{a}| \leq 2.56 \%$;

- linear correlation coefficient: $\mathrm{Rc} \geq \operatorname{minRc}$.

The results of determining the linearity of the technique are shown in Table $\mathbf{5}$.

Table 5

The results of determining the linearity of the method

\begin{tabular}{|c|c|c|c|c|c|}
\hline No. & The content of the analyte, $\%$ & $\mathbf{S}_{\mathrm{i}}$ & $\bar{S}_{i}$ & $\mathbf{X}_{\mathrm{i},} \%$ & $\mathbf{Y}_{\mathrm{i}}, \%$ \\
\hline 1 & 80 & $197.124 ; 196.517$ & 196.821 & 80.0 & 80.3 \\
\hline 2 & 85 & $208.692 ; 208.232$ & 206.362 & 85.0 & 85.1 \\
\hline 3 & 90 & $219.393 ; 219.875$ & 219.634 & 90.0 & 89.6 \\
\hline 4 & 95 & $232.308 ; 231.809$ & 232.059 & 95.0 & 94.7 \\
\hline 5 & 100 & $245.641 ; 246.215$ & 245.928 & 100.0 & 100.3 \\
\hline 6 & 105 & $255.647 ; 256.133$ & 255.890 & 105.0 & 104.4 \\
\hline 7 & 110 & $269.383 ; 268.605$ & 268.994 & 110.0 & 109.8 \\
\hline 8 & 115 & $284.866 ; 284.915$ & 284.891 & 115.0 & 116.2 \\
\hline 9 & 120 & $296.371 ; 296.852$ & 296.612 & 120.0 & 121.0 \\
\hline \multicolumn{4}{|c|}{ Weighed portion of the substance sodium hyaluronate, $\mathrm{mg}$} & \multicolumn{2}{|c|}{$90.5 \mathrm{mg}$} \\
\hline \multicolumn{4}{|c|}{ The content of the main substance in the sodium hyaluronate, $\%$} & \multicolumn{2}{|c|}{$99.4 \%$} \\
\hline \multicolumn{4}{|c|}{ Weight loss during drying of sodium hyaluronate, $\%$} & \multicolumn{2}{|c|}{$12.40 \%$} \\
\hline
\end{tabular}

A graph of the dependence of the reduced area of the chromatographic peak on the reduced $\mathrm{S}_{\mathrm{i}}$ concentration is constructed for the analyte (Fig. 3). We visually evaluated the linearity of the obtained dependence, evaluate the compliance of the linear correlation coefficient Rc of the dependence $Y_{i}\left(x_{i}\right)$ with the criterion of acceptability.

For the linear dependence of the form $Y_{i}=a+b \cdot x_{i}$, the parameters a and $\mathrm{b}$ are calculated by the method of least squares (MLC), guided by the article of the SPhU "Statistical analysis of the results of a chemical experiment". The calculated basic indicators of linearity of the method are given in Table 6.

Compare the absolute value of the free term of the linear dependence with the calculated confidence interval Ga. The free member of the linear relationship should not exceed its confidence interval.

For the linear dependence of the reduced area of the chromatographic peak on the reduced concentration of sodium hyaluronate $|\mathrm{a}| \leq \Delta_{a}(1.9490<2.56) ; \mathrm{R}_{c} \geq \operatorname{minRc}(0.9991>0.9982)$. Therefore, the method is linear in the range of analyte concentration of $80-120 \%$. 


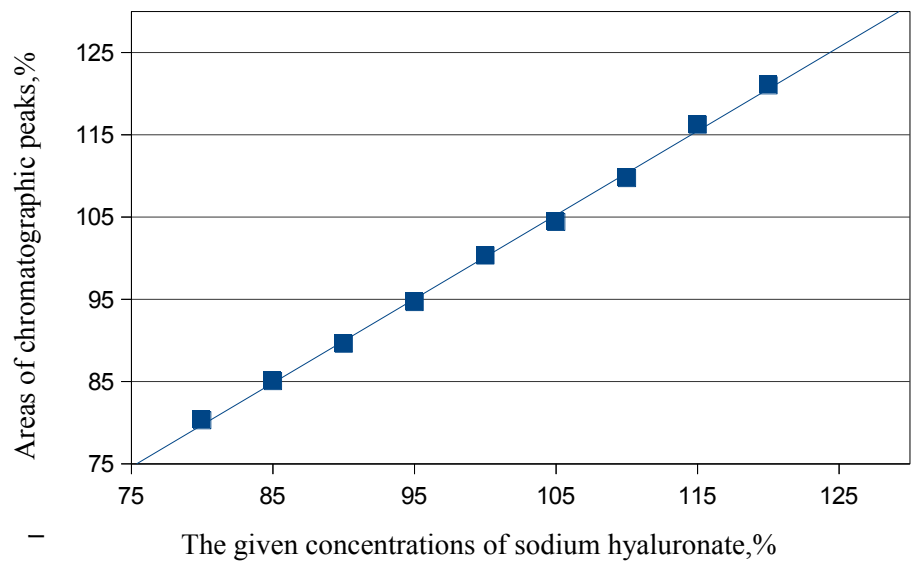

Fig. 3. Graph of the dependence of the reduced area of the chromatographic peak on the reduced concentration of sodium hyaluronate

Table 6

The results of determining the linearity of the method

\begin{tabular}{cc}
\hline Indicator & Results \\
\hline Free member of linear dependence $|\mathrm{a}|$ & 1,9490 \\
Angular coefficient of linear dependence b & 1,0210 \\
$s_{y}^{2}$ & 195,8920 \\
$s_{0}^{2}$ & 0,3670 \\
$\Delta_{\mathrm{a}}$ & 2,56 \\
Fulfillment of the requirement $|\mathrm{a}| \leq \Delta_{a}$ & The requirement is met \\
General correlation index $R_{c}$ & 0,9991 \\
$\min R_{c}$ & 0,9981
\end{tabular}

Criteria of acceptability of control of correctness of a technique:

The correctness of the method characterizes the value of the systematic error $\delta$, ie the deviation of the mean value of the ratio found/entered from 100

The systematic error should be insignificant in comparison with the maximum allowable uncertainty of the analysis results $\max \Delta_{\mathrm{As}}$ :

$$
\delta \leq 0.32 \cdot \max \Delta_{\mathrm{As}}
$$

that is:

$$
\delta \leq 0.51 \% \text {. }
$$

The results of determining the control of the correctness of the method are shown in Table 7.

As can be seen from the table, the value of the systematic error is equal to $\delta=0.12$, which satisfies the condition $\delta \leq 0.51 \%$.

Acceptance criterion control of convergence of the method: the confidence interval of the unit value for the sample of relations found/entered must satisfy the condition $\Delta \mathrm{z} \leq 1.6 \%$.

When checking the convergence of the methods use the results obtained in determining its correctness. The calculations of the confidence interval of the unit value of the ratio were found/entered by the formula $\Delta z=S z t$, found that at $S z=0.578 \%$ the value of $\Delta z=1.08 \%$. The 
value of the confidence interval $\Delta \mathrm{z}$ of the studied method of quantification satisfies the requirements of $\Delta z \leq 1.6 \%$.

Table 7

Results of determining the control of the correctness of the method

\begin{tabular}{ccccc}
\hline No. & $\begin{array}{c}\text { Sodium hyaluronate } \\
\text { content, } \%\end{array}$ & $\begin{array}{c}\text { Ratio found/entered, } \\
\mathbf{z}_{\mathbf{i}}, \boldsymbol{\%}\end{array}$ & $\begin{array}{c}\text { The average value of the } \\
\text { ratio found/entered, } \mathbf{z}, \mathbf{\%}\end{array}$ & $\begin{array}{c}\text { Systematic error, } \\
\mathbf{\delta}, \boldsymbol{\%}\end{array}$ \\
\hline 1 & 80 & 100.39 & \\
2 & 85 & 100.07 & \\
3 & 90 & 99.57 & \\
4 & 95 & 99.65 & \\
5 & 100 & 100.33 & \\
6 & 105 & 99.43 & \\
7 & 110 & 99.76 & \\
8 & 115 & 101.07 & \\
9 & 120 & 100.84 & \\
\end{tabular}

\section{Discussion}

The possibility and benefits of using the HPLC method for quantitative analysis of hyaluronic acid and products of its metabolism have been confirmed by many researchers in the analysis of drugs, cosmetics and in determining the content of hyaluronic acid in biological fluids [16-18]. The chromatograms obtained by us are shown in Fig. 1, 2. The chromatograms shown in Fig. 1, 2 indicate the possibility of identification and quantification of sodium hyaluronate in the combined gel by HPLC. The retention time of sodium hyaluronate in the test sample of the gel coincides with the peak and the retention time of the standard sample of the substance.

A common problem is the quantification of hyaluronic acid in combination drugs or dietary supplements $[13,14,19]$. Thus, oral drugs that can nourish bones and joints contain macromolecular compounds such as hyaluronic acid, methylsulfonylmethane (MSM), chondroitin, glucosamine and collagen. For quantitative analysis of a mixture of hyaluronic acid and methylsulfonylmethane, derivatization of hyaluronic acid using fluorenylmethyloxycarbonyl chloride is used, followed by analysis by liquid chromatography with fluorescence detection. The developed method was linear $(r=0.9983)$ in the range of $5-50 \mathrm{ppm}$, and the limits of detection and quantification were 3.55 and $11.84 \mathrm{ppm}$, respectively [19]. Due to the absence of UV-absorbing chromophore in the structure of hyaluronic acid, its quantitative analysis in the presence of excipients of highly polar nature (sodium phosphate, phosphoric acid, potassium hydroxide, etc.) is quite problematic. The solution to the problem was a new method for the determination of sodium hyaluronate based on liquid chromatography using a UV detector with a variable wavelength set at $205 \mathrm{~nm}$. Specificity/selectivity experiments revealed the absence of interference from excipients, recovery from spiked samples for sodium hyaluronate was 99-102 [14].

The method developed by us allows to quantify sodium hyaluronate in the presence of other active substances (metronidazole benzoate, miramistin) and excipients (carbomer, sodium hydroxide, etc.). The validation of the developed analytical methodology confirms its specificity and reproducibility. Specificity/selectivity experiments revealed the absence of interference from excipients, recovery from spiked samples for sodium hyaluronate was 99.4-101.07. The validation characteristics of the developed methodology must meet the established eligibility criteria $[15,20]$. The spectral purity coefficients $\left(F_{p}\right)$ of the sodium hyaluronate peak on the chromatograms of the model solution are $F_{p} 1=997,665$ and $F_{p} 2=997,802$. The obtained values meet the acceptability criterion $F_{p} \geq 995.0$ and significantly exceed the critical value. The method is linear in the range of sodium concentration of hyaluronate $80-120 \%$, the calculated linear dependence of the re- 
duced area of the chromatographic peak on the reduced concentration of sodium hyaluronate is $|\mathrm{a}|=1.9490 \leq \Delta_{a}=2.56$. The calculated systematic error $(\delta)$ and the confidence interval $(\Delta \mathrm{z})$ meet the eligibility criteria and confirm the correctness and convergence of the developed method of quantification.

Study limitations. The chromatogram of the test gel solution (Fig. 2), in addition to the peak of sodium hyaluronate, contains peaks of response of other substances. We did not identify these substances within the studies. The main criterion was the conformity of the retention time of sodium hyaluronate to the standard sample solution and the absence of the effect of unidentified substances on the accuracy of measurement.

Prospects for further research. Conducting research to study the stability of the developed combined gel, determining the effect of storage conditions, container material on the chemical stability of active substances, in particular sodium hyaluronate.

\section{Conclusions}

1. A method for the identification and quantification of sodium hyaluronate by HPLC using a PL-aquagel-OH, Agilent chromatographic column with a size of $300 \times 7.5 \mathrm{~mm}$ and detection at a wavelength of $210 \mathrm{~nm}$. The retention time of sodium hyaluronate is about $5.02 \mathrm{~min}$ with a symmetry factor of 1.29 .

2. The method allows for qualitative and quantitative analysis of sodium hyaluronate in the combined gel, in the presence of other active substances (metronidazole benzoate, miramistin).

3. The main validation characteristics of the method of quantitative determination of sodium hyaluronate by HPLC are determined. In terms of specificity, linearity, correctness, convergence, the developed methodology meets the criteria of SPhU acceptability.

\section{Conflict of interests}

The authors declare that they have no conflicts of interest.

\section{References}

[1] Sigaeva, N. N., Kolesov, S. V., Nazarov, P. V., Vildanova, R. R. (2012). Khimicheskaia modifikatsiia gialuronovoi kisloty i ee primenenie v meditsine. Vestnik bashkirskogo universiteta, 17 (3), 1220-1241.

[2] Casale, M., Moffa, A., Vella, P., Sabatino, L., Capuano, F., Salvinelli, B. et. al. (2016). Hyaluronic acid: Perspectives in dentistry. A systematic review. International Journal of Immunopathology and Pharmacology, 29 (4), 572-582. doi: http://doi.org/ 10.1177/0394632016652906

[3] Tarasenko, S. V., Kulaga, O. I. (2016). Application of hyaluronic acid preparations for patients with a chronic generalized periodontal disease. Rossiyskiy stomatologicheskiy zhurnal, 20 (6), 340-343

[4] Brzheskiy, V. V., Popov, V. Y. (2018). Modern possibilities of sodium hyaluronate in tear substitutive therapy of patients with “dry eye" syndrome. Clinical Ophthalmology, 18 (4), 179-185. doi: http://doi.org/10.21689/2311-7729-2018-18-4-179-185

[5] Kaskova, L. F., Kulay, O. A., Andriyanova, O. Y., Babanina, S. M., Khmil, E. V., Danilenko, V. V., Tovma, V. V. (2018). The medical drug including hyaluronic acid was used for the treatment of symptomatic gingivitis in children with acute herpetic stomatitis. Bulletin of Problems Biology and Medicine, 2 (4), 334-336. doi: http://doi.org/10.29254/2077-4214-2018-4-2-147334-336

[6] Dahiya, P., Kamal, R. (2013). Hyaluronic acid: A boon in periodontal therapy. North American Journal of Medical Sciences, 5 (5), 309. doi: http://doi.org/10.4103/1947-2714.112473

[7] Mahmood, A., Abdul-Wahab, G., Al-Karawi, S. (2019). Effect of hyaluronan and metronidazole gels in management of chronic periodontitis. Journal of International Oral Health, 11 (3), 158. doi: http://doi.org/10.4103/jioh.jioh_292_18

[8] GOST R 58484-2019 (2019). Non-active surgical implants. Implants based on hyaluronic acid. Standard guide to determining characteristics and conducting trials of hyaluronic acid, as an incipient basis for medical devices.

[9] Savoskin, O., Semenova, E., Rashevskaia, E., Poliakova, A., Gribkova, E., Agabalaeva, K., Moiseeva, I. (2017). A description of different methods used to obtain hyaluronic acid. Scientific Review. Biological science, 2, 125-135.

[10] Sodium Hyaluronate (2016). European Pharmacopoeia 9th. Vol. 2. European Directorate for Qulity of Medicines \& Health Care. Strasbourg, 3583-3585.

[11] Vanhee, C., Desmedt, B., Baudewyns, S., Kamugisha, A., Vanhamme, M., Bothy, J.-L. et. al. (2017). Characterization of suspected dermal fillers containing hyaluronic acid. Analytical Methods, 9 (28), 4175-4183. doi: http://doi.org/10.1039/c7ay01130j 
[12] Orlenko, D. S., Yakovenko, V. K. (2020). Justification of the method for the quantitative determination of metronidazole benzoate in the composition of oromucosus gel. Upravlinnia yakistiu $\mathrm{v}$ farmatsii, 110.

[13] Zebrower, M. E., Kieras, F. J., Brown, W. T. (1986). Analysis by high-performance liquid chromatography of hyaluronic acid and chondrotin sulfates. Analytical Biochemistry, 157 (1), 93-99. doi: http://doi.org/10.1016/0003-2697(86)90201-0

[14] Ruckmani, K., Shaikh, S. Z., Khalil, P., Muneera, M. S., Thusleem, O. A. (2013). Determination of sodium hyaluronate in pharmaceutical formulations by HPLC-UV. Journal of Pharmaceutical Analysis, 3 (5), 324-329. doi: http://doi.org/10.1016/ j.jpha.2013.02.001

[15] State Pharmacopeia of Ukraine: in 3 vol. (2015). Kyiv: Ukrayinskyi naukovyi farmakopeinyi tsentr yakosti likarskykh zasobiv.

[16] Payan, E., Jouzeau, J. Y., Lapicque, F., Muller, N., Payan, J. P., Gegout, P. et. al. (1991). Assay of synovial fluid hyaluronic acid using high-performance liquid chromatography of hyaluronidase digests. Journal of Chromatography B: Biomedical Sciences and Applications, 566 (1), 9-18. doi: http://doi.org/10.1016/0378-4347(91)80106-m

[17] Kakehi, K., Ueda, M., Suzuki, S., Honda, S. (1993). Determination of hyaluronic acid by high-performance liquid chromatography of the oligosaccharides derived therefrom as 1-(4-methoxy)phenyl-3-methyl-5-pyrazolone derivatives. Journal of Chromatography A, 630 (1-2), 141-146. doi: http://doi.org/10.1016/0021-9673(93)80449-i

[18] Zhang, Z., Xie, J., Zhang, F., Linhardt, R. J. (2007). Thin-layer chromatography for the analysis of glycosaminoglycan oligosaccharides. Analytical Biochemistry, 371 (1), 118-120. doi: http://doi.org/10.1016/j.ab.2007.07.003

[19] Harmita, H., Hayun, H., Geofani, M. H. (2020). Quantification of hyaluronic acid and methylsulfonylmethane in dietary supplements. International Journal of Applied Pharmaceutics, 12 (1), 143-148. doi: http://doi.org/10.22159/ijap.2020.v12s1.ff032

[20] Park, S.-W., Lee, W. (2015). Development of a validated HPLC method for the determination of hyaluronic acid in dietary supplement formulations. Bulletin of the Korean Chemical Society, 36, 1270-1273. 